\section{Multivariate Analysis of Variance}

Michael Franzen

Allegheny General Hospital, Pittsburgh, PA, USA

\section{Synonyms}

MANOVA

\section{Definition}

Multivariate analysis of variance (MANOVA) is a generalization of the general linear model of statistical analysis to situations where there are multiple dependent measures (Timm 1993). The independent measures are categorical, and the dependent measures are continuous. The dependent measures can have some degree of correlation among themselves. The analysis results in the F-ratio statistic being calculated for the independent measure, indicating whether different values of that independent measure have a statistically significant effect on either the level of the dependent measures or on the relationship among the dependent measures. As such MANOVA is sensitive to both the profile and the magnitude of the dependent measures. Using multiple regression techniques, the researcher can then determine the relative contribution of the dependent measures to the observed significant difference.

\section{References}

Timm, N. H. (1993). MANOVA and MANCOVA: An overview. In G. Keren \& C. Lewis (Eds.), A handbook for data analysis in the behavioral sciences: Statistical issues (pp. 129-163). Hillsdale: Erlbaum. 